\title{
Research on Optimal Agricultural Insurance Product and Its Effect of Poverty Alleviation
}

\author{
Jian ZHANG \\ School of Insurance \\ Central University of Finance and Economics \\ 39 South College Road Haidian District \\ Beijing 100081, China
}

\begin{abstract}
Agricultural insurance has played a positive role inensuring agricultural production and stabilizing farmers' income, and has become an important financial tool for poverty alleviation for the rural poor in China. Due to different capital levels, the individual farmer will use production technology with different efficiency. This paper establishes some multiple equilibrium models based on agricultural risk and agricultural insurance, and then discusses the effect of agricultural insurance on poverty alleviation under the agricultural risks. It is found that agricultural insurance can effectively reduce the probability of falling into the poverty trap for the farmers whose initial capital is larger than a certain critical value, and can play a good role in poverty alleviation. At the same time, the individualized design for the optimal agricultural product will improve farmers' enthusiasm for Agricultural insurance.
\end{abstract}

Keywords: poverty trap; multiple equilibrium models; the probability of falling into the poverty trap

\section{Introduction}

Targeted poverty alleviation is to bring targeted help to genuinely poor families and populations through policies and measures for poverty alleviation. Since Reform and Opening in China, great achievements have been made in reducing the number of people living in poverty and improving the living quality of the residents. Since the implementation of the targeted poverty alleviation, the number of people living in poverty has reduced by 68.53 million within 5 years starting from 2013,13.7 million per year and nearly 70\% of the poor population. Besides, it broke the trend that the number of people out of poverty decrease year by year since the implementation of the new criterion. As China's economy grows, most of the people living in poverty are in remote rural areas where the agricultural economy is the main economic character, which makes poverty alleviation in the rural areas the most arduous task to build a moderately prosperous society in China. Agricultural insurance plays a positive role in ensuring agricultural development and stabilizing farmer's income and therefore became one of the important financial tools for poverty alleviation.

Without the subsidy, the opportunity cost of the agricultural insurance premium is higher which makes more individuals fall into the poverty trap. Since the central government began to subsidize agricultural insurance premiums in China in 2007,agricultural insurance developed quickly and lead to the rapid growth of the agricultural economy. Measures for Administration of Agricultural Insurance Premium Subsidies by Chinese Government has pointed out that the financial department should carry out policies like providing subsidies for premium in order to encourage and guide both individuals and agricultural production organizations to insure themselves, and promote the market-oriented development of agricultural insurance, and enhance the ability of agriculture to resistant risk. The policy that provides subsidies for agricultural insurance premium has so far become one of the important policies to support the agricultural industry.

According to (Buera,2009), assume individuals with low capital use inefficient production technology while those with high capital use efficient production technology with an extra cost, this paper establishes some multiple equilibrium models based on agricultural risk and agricultural insurance. Assume that the risk of agricultural output to be continuous and introduce the guarantee level of agricultural insurance. Design insurance products from the angle of the guarantee level, farmers can independently choose agricultural insurance under the best guarantee level of insurance. This paper will also discuss the effect of agricultural insurance on poverty alleviation with a certain percentage of government subsidies.

\section{Literature review}

Economists usually define poverty trap as a self-sustaining statement (Azariadis and Stachurski 2005)which means individuals, families, and groups in poverty are in a vicious circle of poverty for a long time and unable to extricate themselves. 
In the available literature, scholars usually use a multiple equilibrium model to study the poverty trap, this model has at least one balance concerned with the low capital while another concerned with the high capital. The existence of multiple balances means there is at least a critical value on the boundary between two areas, individuals whose property is lower than that threshold will converge to a low equilibrium point and fall into the poverty trap while those higher than that will converge to a high equilibrium point and move beyond poverty. Janzen, Carter, and Ikegami (2012) established a multiple equilibrium model in the study of Livestock husbandry in northern Kenya, it turned out that insurance will decrease the loss of herdsmen cost by the drought and they also provide strong evidence that the poverty trap do exist. Kovacevic and Pflug (2011) use the Ruin Theory to analyse the probability of a farmer falling into the poverty trap and the effect insurance have over groups with different property. Barrett, Carter, and Ikegami (2008) use stochastic dynamic model to obtain the tipping point, apply production function with high technology when the property is higher than the tipping point and apply production function with low technology when the property is lower than the tipping point to establish a multiple equilibrium model in order to analyze policies of social security.

A study on China's insurance and poverty alleviation. TUO Guozhu (2011) pointed out that government subsidizing premium is an indispensable part of the agricultural insurance market and a crucial driving forth for the development of agricultural insurance. JIANG Shengzhong, JIA Shibin et al (2015) analysis the effectiveness of subsidies of agricultural insurance based on provincial panel data through super-efficiency analysis method, they believe that subsidizing agricultural insurance by central government plays a positive role in the development of agricultural insurance market.YU Yang (2013)pointed out that the guarantee level and the ratio of subsidies are two crucial factors affecting whether farmers' insurance themselves. China needs to level up the security of insurance gradually and bring differentiated proportional subsidy into forth in order to better policies that provide subsidies for agricultural insurance premium. SUN Wujun, QI Jing(2016)established a stochastic growth model of family capital and studied the effect of insurance on ensuring families get out of the poverty trap during major events. WANG Ren (2016) et al come to a conclusion that the poverty alleviation efficiency of subsidizing agricultural insurance in HuNan province is tolerable and can help agricultural economic in Hunan province to develop through AHP method. XU Rong(2016)et al introduced instrumental variables to start an endogenous discussion based on provincial panel data of the year 2011 and year 2012. The conclusion is that agricultural insurance can use the capacity of insurance companies to compensate the production loss of farmers reasonably, help farmers to resume production and minimize the number of situations of becoming impoverished or becoming impoverished again because of the disaster.

\section{Model and Method}

\subsection{Model without agricultural insurance}

Assume that the agricultural economic system contains a large number of farmers, and each individual has an unlimited life. Each farmer has a different amount of initial capital and reaches maximum the utility of the whole life by choosing the optimal consumption during each period. The optimization problem is as follows:

$$
\begin{aligned}
& \max _{\left\{c_{t}\right\}_{t=0}^{\infty}} E\left\{\sum_{t=0}^{\infty} \beta^{t} u\left(c_{t}\right)\right\} \\
& \text { s.t } c_{t}+k_{t+1}=f\left(A_{t}, k_{t}\right)+(1-\delta) k_{t}, \forall t=0,1,2, \cdots
\end{aligned}
$$

where $\beta$ is the discount factor of utility, $u(\square)$ is the utility function, $c_{t}$ is the consumption in period $t, k_{t}$ is the capital level in period $t, k_{0}$ is the initial capital of the individual, and $\delta$ is the depreciation factor. Assume that the proportion of agricultural output $A_{t}$ is a continuous variable, according to Kovacevic and Pflug (2011), $A_{t}$ obey beta distribution and its Probability Density Function is $g\left(A_{t}\right)$, the probability that the risk won't occur is $p$ and the probability that the risk will occur is $1-p$.The present consumption and the input of the next term will only rely on the output level and depreciated capital stock of the present term. Capitals can't be accumulated by advancing future profit.

Referring to Buera ${ }^{[1]}(2009)$, assumed that expected income $f(\square)$, for an individual in period $t$ is given by :

$$
f\left(A_{t}, k_{t}\right)=\left\{\begin{array}{c}
f^{H}\left(A_{t}, k_{t}\right)=\alpha A_{t} k_{t}^{\gamma_{H}}-\underline{f} k_{t}>\tilde{k} \\
f^{L}\left(A_{t}, k_{t}\right)=\alpha A_{t} k_{t}^{\gamma_{L}} \quad k_{t} \leq \tilde{k}
\end{array}\right.
$$


Where $\alpha$ is the level of technology, $\gamma_{L}, \gamma_{H}$ represent the output elasticity of capital. The high technology is subjected to fixed cost $\underline{f}$, such that the technology is not worth using at low amounts of capital.

the Bellman equation for maximizing the farmers' lifetime utility can be expressed as:

$$
V\left(k_{t}, A_{t}\right)=\max _{c_{t}}\left\{u\left(c_{t}\right)+\beta E\left[V\left(k_{t+1}, A_{t+1} \mid c_{t}, A_{t}\right)\right]\right\}
$$

Assume that the farmers' asset is between 0 and 25, and agricultural production is endangered by agricultural risk. The parameters are set as follows: $\gamma_{L}=0.1, \gamma_{H}=0.5, \alpha=1, \underline{f}=1, p=0.95, A^{1}=1, A^{2}=0.1$, $\beta=0.98, \delta=0.1$, the utility function is: $u\left(c_{t}\right)=\ln ^{c_{t}}, \quad p=0.8, A_{t} \square B(7,4)$ 。 The optimal consumption strategy of farmers with different asset is obtained by solving the eq.(3), which need program with MATLAB, and then numerically simulate the dynamic path of the individual inter-temporal assets of the farmer, as shown in Figure 1.

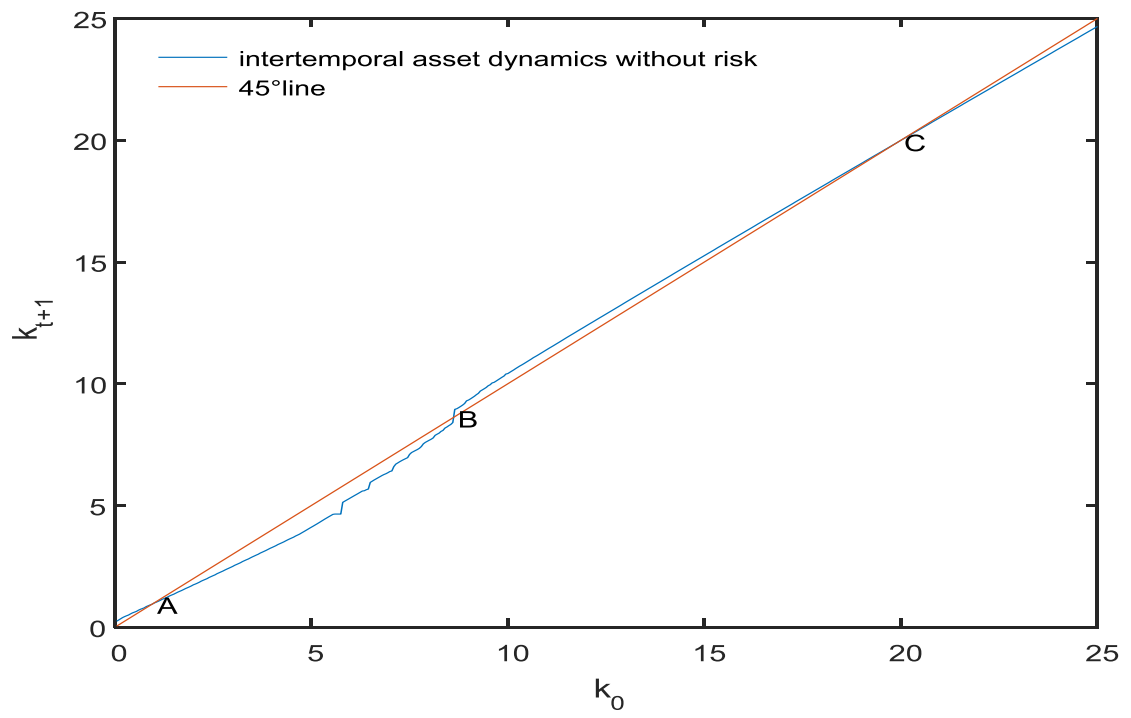

Figure 1: The dynamic path of the individual inter-temporal assets without insurance

As can be seen from Figure 1, point $\mathrm{C}$ is the high equilibrium point in agricultural economics and point $\mathrm{A}$ is the low one. Those below point A are in poverty. Once the capital of farmer households is lower than point B's corresponding values no matter during which period, the farmer will fall into "the poverty trap". After simulating production and risk processes by 10000 times, the probability of falling into the poverty trap can be calculated. The probability of falling into the poverty trap of individuals is shown in Figure 2:

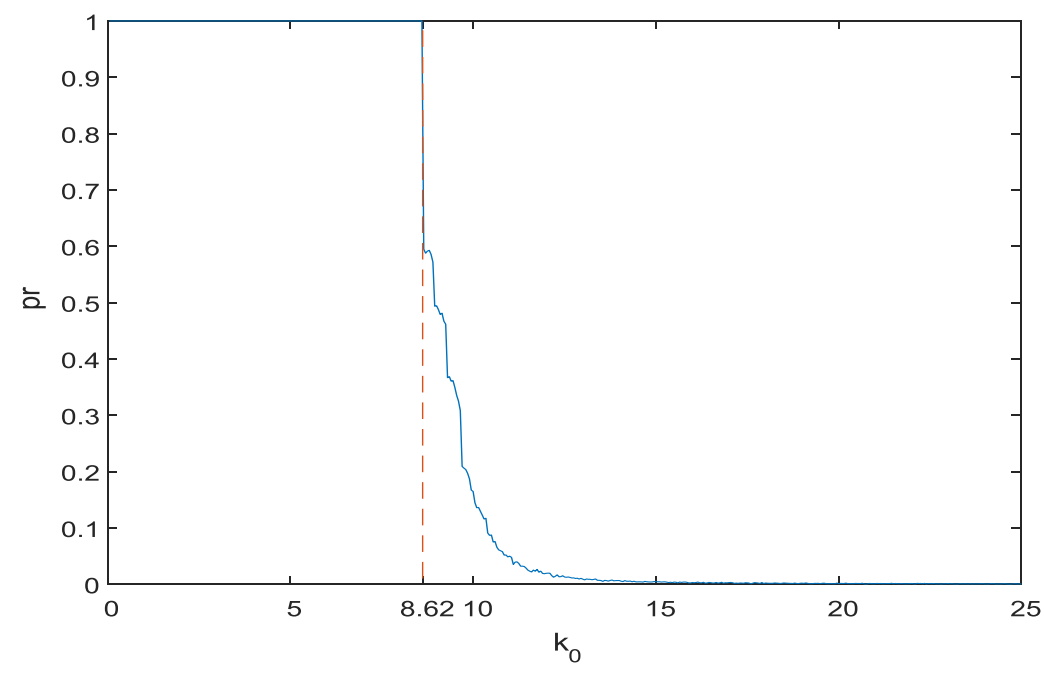

Figure 2: The poverty probability without the agriculture insurance 
As Figure 2 shows, when the initial capital of the individual is lower than 8.6195, the probability of the farmer falling into the poverty trap is 1 which means the farmer will definitely fall into the poverty trap; when the initial capital of the individual is higher than 8.6195 , the farmer is not necessarily falling into the poverty trap and the probability of falling into the poverty trap decreases with the growth of the initial capital level.

\subsection{The agricultural insurance with the guarantee level of $B_{t}$}

Introduce the agricultural insurance with the protection level that can meet the condition that $B_{t} \in[0,1]$,only when $A_{t}<B_{t}$ will trigger the insurance claims. Assume that agricultural insurance is priced according to Expected Value Premium Principle. The premium should be:

$$
m_{t}=(1+\theta)(1-p) \int_{0}^{B_{t}}\left(f\left(B_{t}, k_{t}-m_{t}\right)-f\left(A_{t}, k_{t}-m_{t}\right)\right) g\left(A_{t}\right) d A_{t}(4)
$$

After introducing the agricultural insurance, The optimization problem is as follows:

$$
\begin{aligned}
& \max _{\left\{c_{t}\right\}_{t=0}^{\infty},\left\{B_{t}\right\}_{0}^{1}} E\left\{\sum_{t=0}^{\infty} \beta^{t} u\left(c_{t}\right)\right\} \\
& \text { s.t } c_{t}+k_{t+1}=\max \left\{f\left(B_{t}, k_{t}-m_{t}\right), f\left(A_{t}, k_{t}-m_{t}\right)\right\}+(1-\delta)\left(k_{t}-m_{t}\right), \forall t=0,1,2, \cdots
\end{aligned}
$$

Existing agricultural insurance productions' guarantee level are fixed, in order to increase the variety of the agricultural insurance, the agricultural insurance production with the best guarantee level is designed. Farmers, aiming at reaching maximum the utility of the whole life, can choose insurance productions at any guarantee level.

The optimal consumption strategy of farmers with different asset is obtained by solving the Bellman eq.(3), which need program with MATLAB, and then numerically simulate the dynamic path of the individual inter-temporal assets of the farmer. The agricultural insurance, with fixed guarantee level at 0.8 and with best guarantee level, have different influence over dynamic path of the individual inter-temporal assets, it is shown in Figure 3.

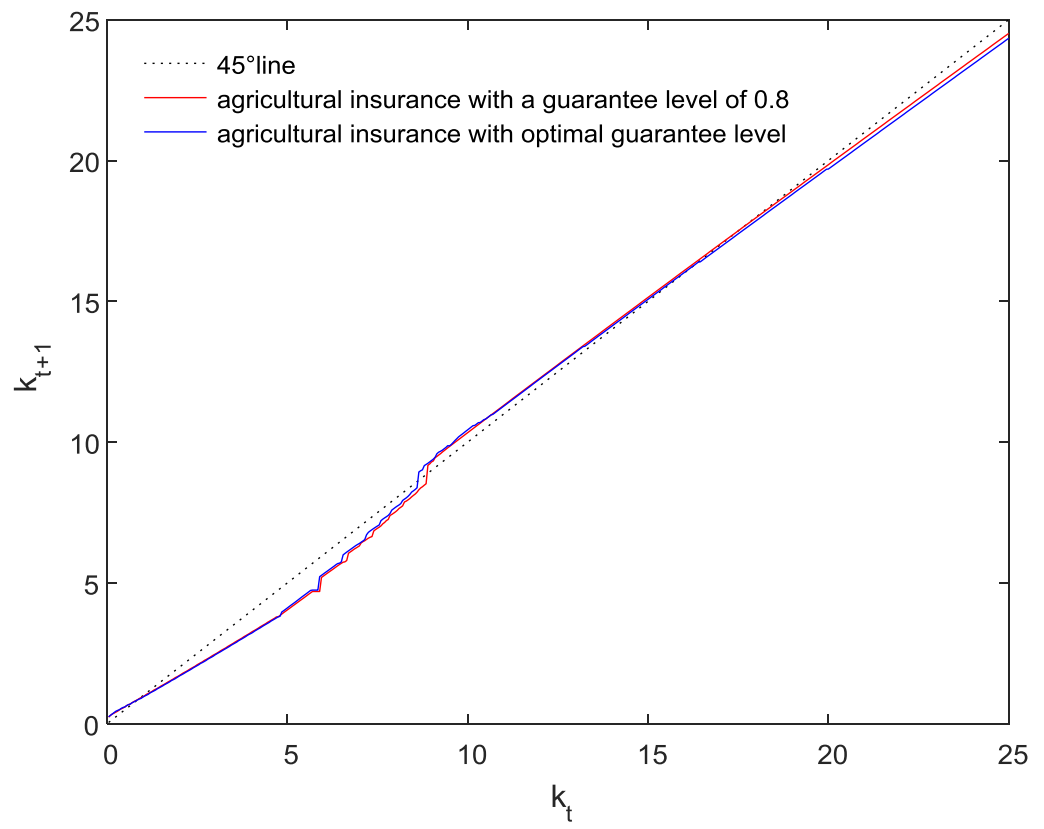

Figure 3: The dynamic path of the individual inter-temporal assets with the optimal insurance

Agriculture insurance has also changed the probability of individuals with different initial capital falling into the poverty trap, it is shown in Figure 4: 


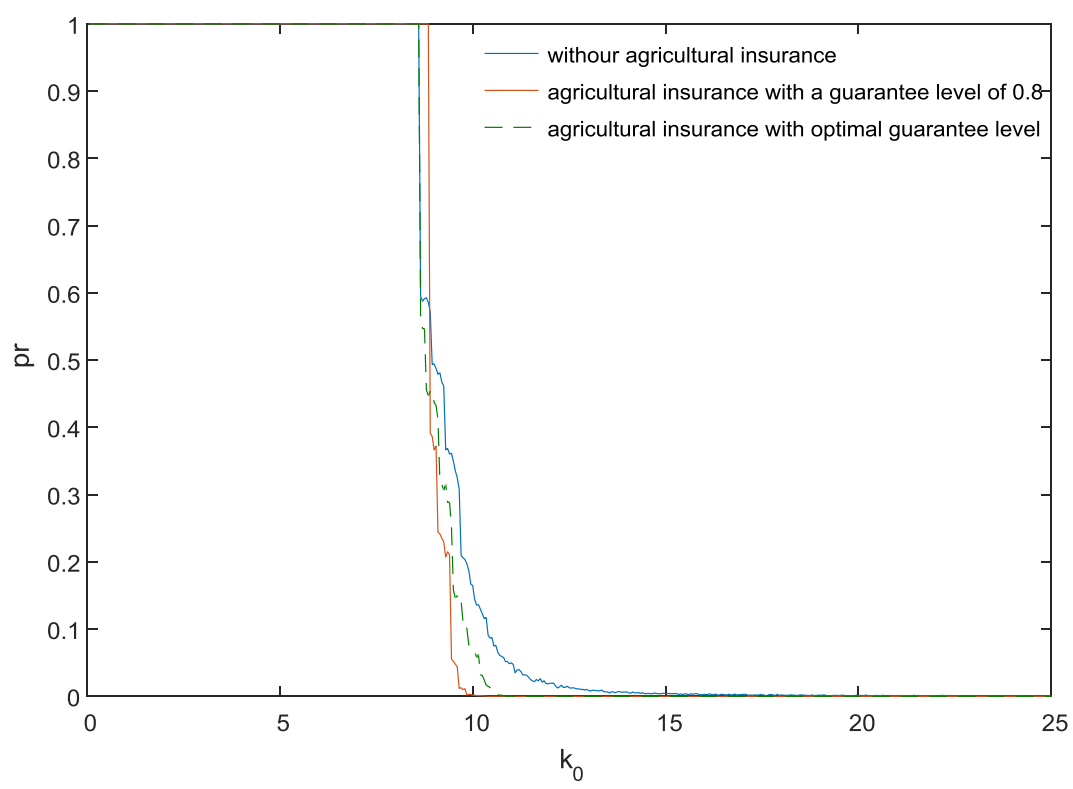

Figure 4:The poverty probability without and with the agriculture insurance

Figure 5 shows the most optimal insurance guarantee level $B_{t}$ of different capital level:

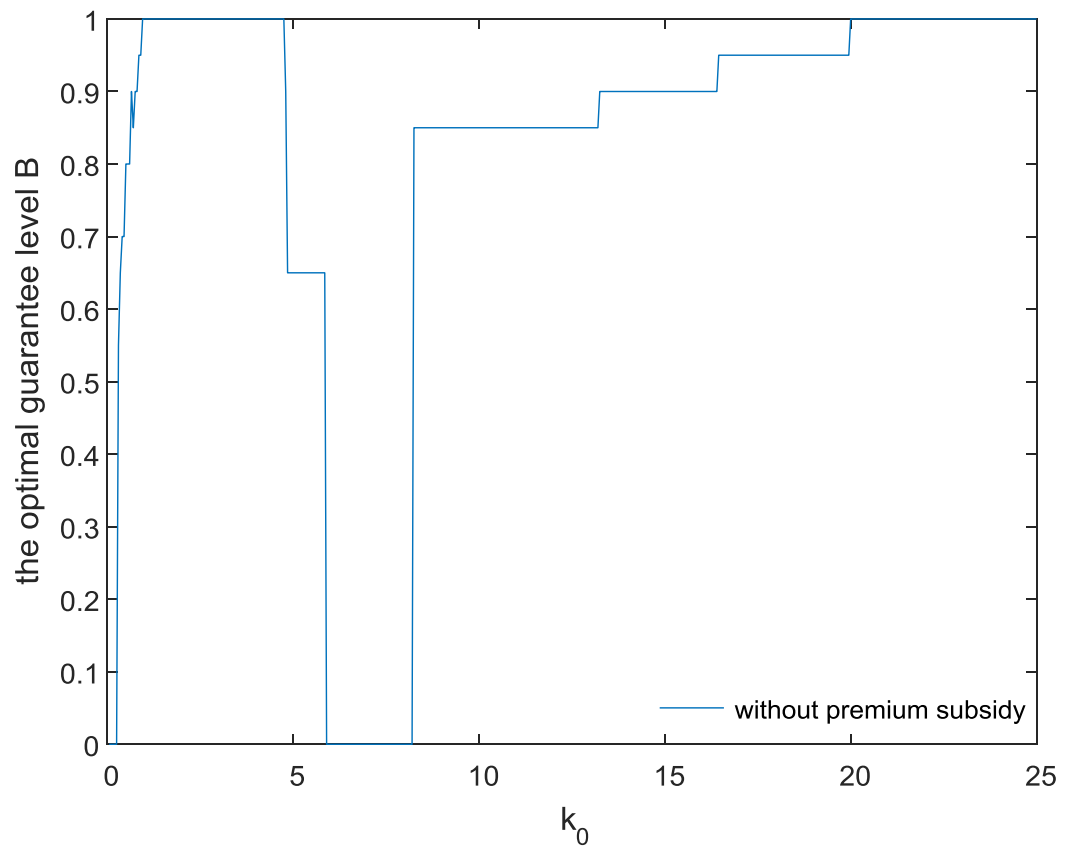

Figure 5: The most optimal insurance guarantee level

As it can be seen from Figure 5, when the capital level of the individual is extremely low, the corresponding most optimal guarantee level 0; with the capital level increases, the corresponding most optimal guarantee level moves in tandem, until it reaches 1; when the capital level falls into a certain section which contains the critical value, the corresponding most optimal guarantee level is 0 ; when the capital level is over that critical value, the most optimal guarantee level increases as the capital increases, until it reaches 1.

3.3The most optimal agricultural insurance with subsidies of the premium from the government

The subsidies of the premium from the government influence farmer's choice about the most optimal guarantee level, it is shown in Figure 6: 

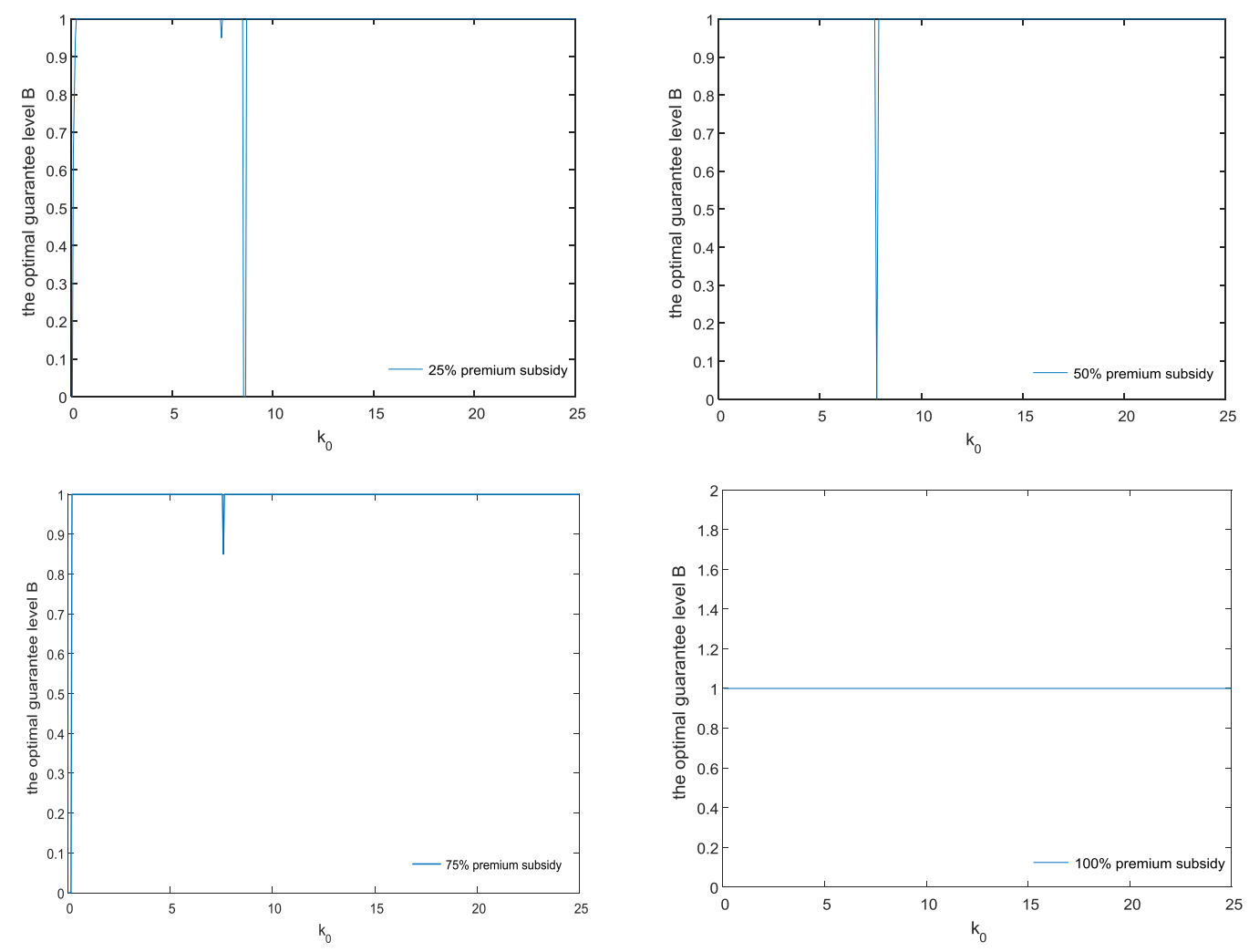

Figure 6: The most optimal insurance guarantee level with premium subsidies

It can be seen from Figure 6, as the ratio of subsidies from the government of insurance premium increases, the most optimal insurance guarantee level of individuals $B_{t}$ increases; when the ratio of subsidies from the government reaches a certain level, the most optimal insurance guarantee level of individuals is 1 except those who is near the critical value of the poverty trap, which means they will buy full insurance. When the ratio of subsidies is $100 \%$, all farmers will choose full insurance provided by the government.

Compare the poverty alleviation effect of insurance productions with the most optimal insurance guarantee level at different ratio from the government, the probability of falling into the poverty trap is shown in Figure 7:

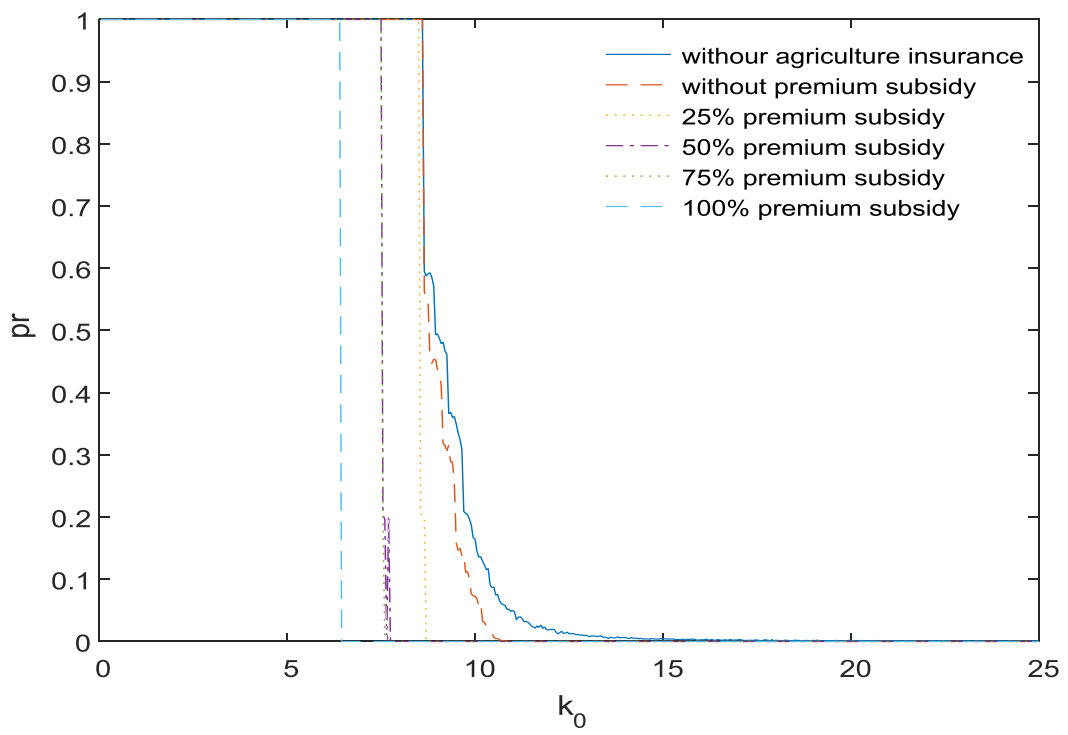

Figure 7:Theprobability of poverty with the most optimalagricultural insurance under different subsidy ratios 
Agricultural insurance with fixed guarantee level and the most optimal insurance guarantee level has different influence over equilibrium, it can be seen from Table 1:

Table 1:The influence of the agricultural insurance with subsidies to equilibrium

\begin{tabular}{|c|c|c|c|}
\hline & Low equilibrium & Threshold & High equilibrium \\
\hline No insurance & 0.9501 & 8.6195 & 19.9345 \\
\hline $\begin{array}{ll}\text { Insurance } & \text { without } \\
\operatorname{subsidy}\left(B_{t}=0.8\right) & \end{array}$ & 0.9000 & 8.8768 & 17.5897 \\
\hline $\begin{array}{l}\text { Insurance with a subsidy ratio of } \\
25 \%\left(B_{t}=0.8\right)\end{array}$ & 0.8999 & 8.6739 & 17.8015 \\
\hline $\begin{array}{l}\text { Insurance with a subsidy ratio of } \\
50 \%\left(B_{t}=0.8\right)\end{array}$ & 0.8997 & 8.5709 & 18.0500 \\
\hline $\begin{array}{l}\text { Insurance with a subsidy ratio of } \\
75 \%\left(B_{t}=0.8\right)\end{array}$ & 0.8999 & 8.2207 & 18.2997 \\
\hline $\begin{array}{l}\text { Insurance with a subsidy ratio of } \\
100 \%\left(B_{t}=0.8\right)\end{array}$ & 0.9000 & 7.5711 & 18.5528 \\
\hline Optimal insurance without subsidy & 0.8500 & 8.6213 & 16.3423 \\
\hline $\begin{array}{l}\text { Optimal insurance with a subsidy } \\
\text { ratio of } 25 \%\end{array}$ & 0.8001 & 8.5232 & 16.4696 \\
\hline $\begin{array}{l}\text { Optimal insurance with a subsidy } \\
\text { ratio of } 50 \%\end{array}$ & 0.8001 & 7.5276 & 16.6291 \\
\hline $\begin{array}{l}\text { Optimal insurance with a subsidy } \\
\text { ratio of } 75 \%\end{array}$ & 0.8001 & 7.5244 & 16.6989 \\
\hline $\begin{array}{l}\text { Optimal insurance with a subsidy } \\
\text { ratio of } 100 \%\end{array}$ & 0.8001 & 6.4295 & 17.2503 \\
\hline
\end{tabular}

It can be seen from Figure 7 and Chart 1,the higher the ratio of subsidies of the premium is, the lower the critical capital level is, which means fewer farmers will fall into the poverty trap. The low equilibrium of the long-term capital nearly doesn't change, however, the high equilibrium is obviously higher. At the same ratio of the subsidies from the government, the poverty alleviation effect of the agricultural insurance production with the most optimal insurance guarantee level is better than that with the fixed guarantee level at 0.8 . Take the ratio of subsidies at $50 \%$ for example, the critical value of the probability individuals falling into the poverty trap when bought an agricultural insurance production with fixed guarantee level is 8.5709 , slightly lower than the critical value without agricultural insurance which is 8.6195; The critical value when bought an agricultural insurance production with most optimal guarantee level is 7.5276 , obviously much lower than 8.6195 , which means fewer individuals fall into the poverty trap. When the ratio of subsidies from the government reaches a certain level, it could help more individuals move beyond poverty and achieve the goal of supporting the poor.

\section{Conclusions}

In order to avoid individuals falling into the poverty trap, achieve poverty alleviation of the poor population in rural areas, we established some multiple equilibrium models based on agricultural risk and agricultural insurance, assumes that the risk of agricultural output to be continuous and discussed the effect of agricultural insurance on poverty alleviation. we reached following conclusions.(i)Without the agricultural insurance, when the initial capital of the individual is lower than the critical value the farmer will definitely fall into the poverty trap, which means the probability of the falling into the poverty trap is 1 . When the initial capital of the individual is higher than the critical value, the farmer may fall into the poverty trap and the probability of falling into the poverty trap decreases with the growth of the initial capital level.(ii) After introducing agricultural insurance ,the critical value of falling into the poverty trap is higher than without agricultural insurance, this is because purchasing the insurance decreases the capital for agricultural production and therefore lead to falling into the poverty trap.(iii)This paper sets the ratio of subsidies from the government at $25 \%, 50 \%, 75 \%, 100 \%$ and discuss the effect of different ratio of subsidies have over the equilibrium of the long-term capital level and the probability of falling into the poverty trap. 
The higher the ratio of subsidies from the government of the premium is, the lower the critical capital level of falling into the poverty trap is, which means fewer farmers will fall into the poverty trap. Insurances do have some effect over poverty alleviation.(iv)Compare the agricultural insurance production with fixed guarantee level and the agricultural insurance production with the most optimal guarantee level chosen by individuals according to the principle that one should reach maximum the utility of the whole life, when there's no subsidies from the government, the critical value of falling into the poverty trap of both is higher than that without agricultural insurance. When at the same ratio of the subsidies from the government, the poverty alleviation effect of the latter one is better than the former. Aiming at farmers with different initial capital, agricultural insurance production with different guarantee levels should be designed, it can also increase the variety of insurance productions and motivate farmers to insure themselves. Insurances can be more effective over poverty alleviation with policies that government provide subsidies for insurance premium.

\section{References}

Buera F J. (2009).A dynamic model of entrepreneurship with borrowing constraints: theory and evidence[J]. Annals of Finance, 5(3-4):443-464.

Azariadis, C. and J. Stachurski. (2005) . "Poverty Traps", In P. Aghion and S. N. Durlauf, eds. Handbook of Economic Growth. Elsevier,Vol. 1, Part A, Chap.5, 295-384.

Janzen S A, Carter M R and Ikegami M.(2012). Valuing Asset Insurance in the Presence of Poverty Traps: A Dynamic Approach[C].Economics Association's 2012 AAEA Annual Meeting, August 12-14, 2012, Seattle, Washington.

Kovacevic R M, Pflug G C.(2011). Does Insurance Help to Escape the Poverty Trap?-A Ruin Theoretic Approach[J]. Journal of Risk \& Insurance,78(4):1003-1028.

Barrett C B, Carter M R adn Ikegami M. .(2008).Poverty Traps and Social Protection[J]. Social Science Electronic Publishing, 20(35):749-761.

TUO Guozhu.(2011).A Study on Government Subsidies to Agricultrual Insurance[J].Research on Economics and Management,(4):80-85.

JIANG Shengzhong, JIA Shibin and JIANG Shikun. (2015) An Analysis of the Efficiency and Influencing Factors of Agricultural Insurance Subsidies — Based on the Provincial Panel Data between 2010 to 2013 [J].Insurance Studies,(12):67-77.

YU Yang. (2013) Research on the Differentiated Policy of Premium Subsidy for Agricultural Insurance Based on the Coverage Level: The Experience of America and the Choice of China[J].Issues in Agricultural Economy, 34(10):29-35.

SUN Wujun,QI Jing.(2016). Insurance security, family capital growth and poverty trap[J].Journal of Management Sciences in China, 19(12):71-82.

WANG Ren,ZOU Xi-xi and LIU Si-han. Evaluation of the Poverty Alleviation Efficiency in Hunan Province Based on AHP Method[J].Commercial Science Research.(2):123-128.

XU Rong,ZHAO Chang and ZHAO Canyu. The Relationship between the Government Natural Disaster Reliefand the Agriculture Insurance Market-Empiracl Evidence Based on the Provincial Panel Data of China[J].Insurance Studies, (12):74-79. 